\title{
Chronic treatment with valproate protects INS1 cell from palmitate-induced ER stress and apoptosis by inhibiting GSK3 $\beta$
}

\author{
Shan Huang ${ }^{1 *}$, Wei Wu' ${ }^{1}$ Yan Liang ${ }^{1}$, Qin Ning ${ }^{2}$, Xiao-ping Luo ${ }^{1}$ \\ From 7th APPES Biennial Scientific Meeting \\ Nusa Dua, Bali. 14-17 November 2012
}

\section{Objective}

Reduction of $\beta$-cell mass is increasingly recognized as one of the main contributing factors to the pathogenesis of type 2 diabetes. Chronic free fatty acid (FFA) exposure has been shown to induce endoplasmic reticulum (ER) stress that may contribute to promoting pancreatic $\beta$-cell apoptosis. In the present study, we first investigated whether anticonvulsant sodium valproate (VPA), at clinically relevant doses, protects pancreatic $\beta$-cell from palmitate-induced apoptosis and the mechanism underlying anti-apoptosis.

\section{Methods and results}

INS1 cells exposed to $0.25 \sim 1.0 \mathrm{mM}$ palmitate for $24 \sim 48 \mathrm{~h}$ under serum-free conditions showed marked apoptosis in time- and concentration-dependent as assessed by CCK- 8 assay, Hoechst 33342/PI, flow cytometric cell apoptosis assay and electron microscopy. Palmitate triggered ER stress and apoptosis in INS1 cells as evidenced by increased mRNA levels of C/EBP homologous transcription factor (CHOP), activating transcription factor 4 (ATF4) and X box-binding protein 1 (XBP-1) in a timedependent fashion. Western blot analysis also showed significant increase of $\mathrm{CHOP}$ and caspase- 3 in protein level. We also found that palmitate activated GSK3 $\beta$ by inhibiting phosphorylation at serine 9. While chronic, not acute, $1 \sim 2 \mathrm{mM}$ VPA and $2 \mathrm{mM} \mathrm{LiCl}$ remarkable reduced palmitate-induced cytotoxicity. Furthermore, INS1 cells treated with 10 20 $\mu \mathrm{M}$ TDZD-8, a specific GSK3 $\beta$ inhibitor, also elicited cytoprotective responses against $0.25 \sim 0.5 \mathrm{mM}$ palmitate for $6 \sim 48 \mathrm{~h}$ and decreased mRNA level of CHOP, but not ATF4 or XBP-1. The protein levels of CHOP, caspase- 3 and GSK3 $\beta$ activity were remarkable reduced by co-treatment of INS1 cells with $0.25 \mathrm{mM}$ palmitate and 1 mM VPA, compared with $0.25 \mathrm{mM}$ palmitate only. Finally, down-regulation of CHOP expression in INS1 cells by small interfering RNA (SiRNA) did not show apparent cytoprotective responses against $0.25 \mathrm{mM}$ palmitate.

\section{Conclusion}

ER stress and GSK3 $\beta$ involved in palmitate-induced $\beta$-cell apoptosis, however, GSK3 $\beta$ other than ER stress is likely playing a more prominent role. Valproate protected pancreatic $\beta$-cell from palmitate-induced apoptosis and ER stress by inhibiting GSK3 $\beta$.

\section{Authors' details}

${ }^{1}$ Department of Pediatrics, Tongji Hospital, Tongji Medical College, Huazhong University of Science and Technology, Wuhan, China. ${ }^{2}$ Department of Infectious Diseases, Tongji Hospital, Tongji Medical College, Huazhong University of Science and Technology, Wuhan, China.

Published: 3 October 2013

doi:10.1186/1687-9856-2013-S1-O21

Cite this article as: Huang et al:: Chronic treatment with valproate protects INS1 cell from palmitate-induced ER stress and apoptosis by inhibiting GSK3 $\beta$. International Journal of Pediatric Endocrinology 2013 2013(Suppl 1):O21. 